\title{
DISTANCE LEARNING - A NEW ERA OF THE MEDICAL EDUCATION
}

\author{
Ivanov Kr., V. Ignatov, N. Kolev, An. Tonev \\ Department of General and Operative Surgery, Prof. P. Stoyanov Medical University of Varna
}

Reviewed by: Prof. A. Klisarova

\begin{abstract}
Recently, the number of distance learning programs offered by several American and European universities substantially increases. A lot of conventional universities are currently involved in postgraduate distance learning provision, with new courses planned in every subject area. In Bulgaria there is no experience in this field yet although an essential improvement of the computerized infrastructure in the Bulgarian universities and their libraries has been achieved. The Medical University of Varna has already performed successful telemedicine and teleconference experiments. On January 11, 1998, the first seance of Telecommunication Bridge between these two university institutions was successfully carried out. An ISDN connection was realized. The Intel ProShare Video System 500 was installed and used. A semiprofessional JVC M camera was made use of. The Information Centre of the Medical University of Varna is currently involved in a series of activities such as video teleconferencing, preparation of interactive lectures and seminars, multimedia projections, medical videotape projections for small groups of medical post-graduate students, etc. The future of the medical university education in Bulgaria depends on the economic stabilization and growth, on the enthusiasm of both teachers and students sharing the will to be competitive on the European and even world market under the conditions of globalization as well as on their active involvement in the international collaboration networks.
\end{abstract}

The new millennium of the information society requires new attitudes towards the challenges of future ideas and up-dated approaches in solving the dilemmas of present day realities. University education increasingly focuses the attention of the academic community worldwide on the necessity to properly making use of the so-called new information and telecommunication technologies (24) undoubtedly contributing to the improved effectiveness of both research and education.

Over the last decade, the number of distance learning (DL) programs offered by several American and European universities has shown a substantial increase. A lot of conventional universities are currently involved in postgraduate DL provision, with new courses planned in every subject area. The terms 'distance learning' and 'off-campus' are often used interchangeably in Canada and in the US. In England, e.g., the Open University and the University of London External Degree Program deserve a special attention. More and more 'traditional', campus-based universities have moved towards provision of courses off-campus, either through franchising arrangements with colleges or through DL (23). The expansion has occurred particularly

Address for correspondence:

K. Ivanov, Dept. of General and Operative Surgery, St. Marina University Hospital, Prof. P. Stoyanov Medical University of Varna; BG-9002 Varna, 1, Hristo Smirnenski Street, Bulgaria;

e-mail: teraton@abv.bg in relation to postgraduate provision, since DL arranged for structural support for part-time learning is likely to be an effective pedagogy for mature students who are in full-time employment. Not only can such students, it is argued, study in their own time and at their own pace, but their program of study can be related to their own work interests and professional development. Courses leading to Masters degrees for those in commerce and industry are particularly in evidence, although there are many other professional needs now serviced through DL arrangements, e. g. in law, social work, dentistry, etc. The very fact that DL students have, in general, no ready access to campus facilities means that they present a different challenge to a university provider than do on-campus students. There is a large problem of coordination: within universities, between academic departments and the library, between course providers and their students, and between universities and public libraries. The importance of these matters is highlighted by recent developments in the assessment of teaching quality. Many principles of quality assessment will apply equally to distance and full-time postgraduate students.

The first underlying theme in DL is that of learner autonomy as the effectiveness of DL is often predicated on the encouragement its provides for active, independent learning, particularly at the postgraduate level when students are engaged in literature searches and investigative work. The second theme is that of the place of information technology 
and telecommunications. There is potential of electronic information access for radically altering the way learning takes place. The idealized future scenarios, in which relevant and required information passes between students, course providers, and librarians at the press of a button, are still far from the reality. Obviously, however, facilities of advanced technologies will allow literature searches from a student's home, videoconferencing $(3,5,3)$, etc.

Comprehensive literature review on DL from the UK, North America and Australia carried out by Unwin et al. (23) failed to detect any research which brought together the perspectives of the different DL stakeholder groups (DL students, university and public librarians, and course providers). These authors performed the first in-dept analysis of the key stakeholders. They concluded that in the last decade of the XX century, in the UK, as in the USA, Canada, and Australia, the significant recent expansion in the number of students on DL courses has not been matched with the implementation of measures that will effectively meet library needs. There is university librarians' awareness of the somewhat ad hoc and unsatisfactory state of affairs currently prevailing, coupled with a willingness and desire to secure more effective services for DL students.

In Bulgaria, however, we are far from the experiences with DL gained in these countries. On the other hand, in the recent decade of democratization of socio-political life in Eastern Europe, an essential improvement of the computerized infrastructure in the Bulgarian universities has been achieved. In the university buildings themselves, most students have permanently free individual access to Internet, electronic library catalogues, videotape and multimedia projections, etc. A leading position among the medical university libraries in Bulgaria has already been occupied by the Library and Information Service at the Medical University of Varna (15). In its 40-years history, the library has introduced for the first time in Bulgaria a lot of modern information resources.

Let us briefly mention some of them:

i) the electronic version of Current Contents, the 'Life Sciences' series (Current Contents on Diskette) of the Institute for Scientific Information (Philadelphia, PA, USA) already in 1989 when this revolutionary technology appeared on the world information market;

ii) MEDLINE on CD-ROM through OVID since 1992;

iii) DataTrek and GLAS under Windows NT library network and electronic catalogue;

iv) Cochrane Library, ProQuest Medical Library, and UpToDate data bases on CD-ROM;

v) Medical videotapes from the USA and Switzerland;

vi) Medical textbooks, atlases, journals and congress proceedings on CD-ROM;

vii) Satellite Internet connection since 2002, etc.

There exists a dialectic relationship between education and research. That is why it is reasonable to apply the theoretical foundations and practical achievements gained in the social studies of science dealing with research organization to the organization of university education. One of the essential peculiarities of contemporary scientific activity has been formulated as the unity of the three "I" institutionalization, internationalization, and interdisciplinary (22) of science and university education. United efforts of interdisciplinary minded scientists warrant a timely and correct solving of complex problems of the world of nature and man and their successful subsequent management. An optimally institutionalized, problem-oriented scientific activity is more effective than a traditional gross discipline-based one. International cooperation occupies a permanently enhancing relative share particularly when expensive tasks should be rapidly solved.

Contemporary and future educational needs impose a timely orientation and adaptation of teacher's own education towards these regularities of development. The specialists and researchers of the new millennium are educated, trained and post-educated today under the conditions of the existing university educational infrastructure that deserves, in most cases worldwide, substantial reconstruction and optimization facing not only national but also international standards of quality. That is why the disadvantages and pitfalls of the local university curricula could and should be overcome by the contemporarily designed forms and means of expanding DL. Thus the opportunities of the modern interpersonal communications being extremely enlarged by the continuously growing world-wide-web environment could create much more optimal preconditions for gradual or even at a leap transition from individual and group higher education and training into individual and team research work.

Recently, numerous publication deals with analyses of tools and means of computerized, web-based continuing medical education and DL in biomedicine and clinical medicine as well actively applied in many countries $(4,6,9,10,11,13)$. Let us mention some of these promising achievements of enthusiastic interdisciplinary teams and their challenging nature.

McPhee and Niihr (14) accept that with the delivery of DL in today's society, the changing roles of both the teacher and the learner need to be seriously considered. International education currently faces difficulties in facilitating cross-cultural learning. While problems of limited communications technologies, lack of teacher training, inadequate competence of university administration and general cultural differences may be known, global changes call for the development of new pedagogies with new communication technologies in ways, which are sensitive to issues of cultural diversity.

According to Pardue (18), DL has attracted enthusiastic supporters and detractors. Few view DL with neutrality. It is this divergence of opinion that has fueled the debate over the academic value of DL. A valid evaluation of the educational benefits or deficiencies of DL may require additional long-term studies. For some academic traditionalists, DL is viewed as the fusion of education and commerce and borders on the repugnant. Others embrace DL not only because it may provide a source of much needed revenue, but also because it allows for the low-cost delivery of information to a nontraditional pool of students. 
Becich (1) describes the effect on pathology laboratory of functional genomics and emphasizes the role of informatics and tissue banking at the molecular age of medicine. The laboratory information systems are comprehensively analyzed. It is suggested that the devices that feed them information should be modified in order to adapt to greater volumes of data for the new testing modalities necessitating the understanding of sophisticated fluorescence detection methods and image processing. Timely training pathologists in pathology informatics and bioinformatics, i. e., pathobioinformatics, are of essential importance in the post-genome era. Bioinformatics is broadly defined as the discipline of informatics applied to genomics, biosciences, clinical research, and biomedical/health informatics (16). A large number of Web-based bioinformatic resources run the full spectrum from on-line tutorials, courses, and seminars to fellowship opportunities (1). The Advancing Pathology Informatics, Imaging and the Internet (APIII) founded in 1995 have been endorsed by many pathology organizations as excellent educational resource (1) and plays, obviously, an important role in this respect.

Konig et al. (12) discuss the revised surgical curriculum in Gottingen is to demonstrate how medical education with a high didactic level including multimedia teaching can be realized despite large student numbers. Duties both in patient care and education are coordinated through integrated organisation. Educational content and structure are made transparent by online guidebooks. In the surgical examination course and the practical course in surgery, patient-oriented tuition takes place consistently in small groups. The teaching studio provides additional aids such as interactive CD-ROMs, online research, textbooks, ultrasound equipment, examination and suturing dummies. Curriculum-relevant information, including the weekly case examples and instruction guides for clinical practical experience, is presented on an Internet website.

Sekikawa et al. (21) examine the effect of perception of downloading speed on the evaluation of web-based lectures. They postulate that one way to harness the benefit of education on public health education in order to improve global health in the $21^{\text {st }}$ century is to globally share lectures on public health through the Internet. A super course comprising of web-based learning modules on epidemiology in a standardized format with the size of each web page less than 10 kilobytes was developed. A cross-sectional observational study was conducted to investigate the association of the perception of the access speed to Web-based lectures by teachers with their perception of lecture quality. The perception of the quality of Web-based lectures is related to the speed of access to a web page. The speed of access may be as important, if not more important, as the content itself. To share educational materials on the Web globally for teachers, one must consider not only the content, but also how people at local sites gain access to the Internet.

Dietel et al. (7) illustrate the role of the International Union Against Cancer (UICC) Telepathology Consultation Center (TPCC) for improvement of consultations for pathologists in cancer detection. The morphologic diagnosis of tu- mor specimens with precise tumor typing, staging, and grading remains the basis of almost all cancer treatments. Facilitating the communication between pathologists and the exchange of cases, telepathology gains more and more importance. To benefit from this technical development, the UICC has decided to establish a UICC-TPCC for interested pathologists around the world. Telepathology makes the distribution of new developments of diagnostic standards, e.g., of the TNM system, WHO terminology, new tumor classifications, and updated information on actual technologies, globally accessible in a direct and rapid way. It also enables a high quality of education and teaching. Gomez and Clark (8) explore the implications of the Internet for oncology nursing practice, education, and research. They conclude that the Internet has influenced nearly every aspect of society. Besides Internet access, quality of information, and privacy of data transmitted are among the greatest challenges that face oncology nurses who integrate this technology into practice.

Rosser et al. (20) recommend minimally invasive surgical training solutions for the new millennium when the Internet will play an increasing role in distant education. Video and audio streaming techniques will allow the deployment of content previously shackled to a CD-ROM platform. CD-ROM interactive technology can help in developing clinical judgment with innovative strategies, such as Objective-Based Clinical Competency Evaluation Scenarios. Telecommunications will fuse the components of a coordinated DL strategy and allow the availability of new training capabilities in the form of teleproctoring and telementoring to hospitals, no matter what their size or location. It is concluded that these components combined enable the realization of a continuing education program in this field that is readily available to hospitals worldwide.

Moehr and Grant (17) argue that the evolution of consumer health informatics in the last decade has had a profound impact on the practice of medicine, on patient-physician relations and, hence, on the requirements for medical education. The different access to information and how it is used in educational environments will dramatically affect how curricula are structured both at undergraduate and postgraduate levels. The impact of health informatics on medical education is further elaborated, and the requirements on infrastructure in support of this education are detailed. This infrastructure goes beyond instructional laboratories and includes academic units for medical informatics, funding resources and adjudication capacity for health informatics research and their integration into the Canadian research organization and the new Canadian Institutes of Health Research.

Brittain and Noris (2) discuss the education and training in health information management in the context of national information strategies in Great Britain, North America, Australasia and other countries. International activities in the development of generic courses for education and training, the need for education and training, the content of courses, and methods of delivery, including Internet-based training and education are described. Governments and 
health authorities in many countries have recognized the urgent need for a highly educated and trained workforce in information management.

Patel (19) presents a conceptual overview of the current challenges and use of the Internet for improving asthma management through timely and tailored education and appropriate access to health care expertise. With increased understanding of integrated disease management and the technostructural as well as psychodynamic issues related to Internet use, further refinement and evolution of the Internet and related technologies may drastically improve the way we monitor, educate, treat, and establish policies for this global problem while attending to individual or local community needs.

Teleconference means and Intranet/Internet methods were introduced aiming at demonstrating the modern telecommunication technologies. By means of an Intranet connection with the auditorium of surgery in the university hospital, details of this economic and sparing surgical intervention were presented by mass media as well. The course of the operation was observed on 20 " colour monitor as well as distantly on 25 " computer monitor where teleconference software was organized. The consulting physicians observed on several 15" monitors and on 14" and 20" videomonitors, too. The purpose of this experiment was to test the capacities for transfer of data, images, and hospital information after the standard of $115 \mathrm{kbit} /$ network. The success was ensured by the effective network utilization and its proper enlargement.

In the same year, the scientific and technical collaboration between the Medical Faculty of the Aristotelian University of Thessaloniki, Greece, and the Medical University of Varna, Bulgaria started. In 1999, a telecommunication connection between these institutions was created. The medical telemetric network aims at enlarging the existing collaboration between the scientists and medical students from these universities. Greece provides the financial support within the technical aid to the neighboring countries. These facilities will be used for improvement of faculty's qualification and optimization of student's graduate and post-graduate education.

The following main services can be provided:

i) DL of students and post-graduate students

ii) Teleconferencing on medical subjects

iii) Telemedicine activity

iv) Elaboration and fulfillment of joint projects

v) Distant access to electronic libraries

vi) Electronic mail

vii) Access to Internet

viii) Access to university hospital data bases, etc.

The first realized telesurgical project in Medical University, Varna was carried out in 1998, with first laparoscopy cholecystectomy, presented by Ass. prof. K. Ivanov by guidance of prof T. Temelkov to specialists, students and media in University auditorium. On January, 2000, the first international seance of Telecommunication Bridge between these two university institutions was successfully carried out. An ISDN connection was realized. The Intel
ProShare Video System 500 was installed and used. A semiprofessional JVC M camera was made use of. The Information Centre of the Medical University of Varna is currently involved in a series of activities such as videoteleconferencing, preparation of interactive lectures and seminars, multimedia projections, medical videotape projections for small groups of medical post-graduate students, etc.

The future of the medical university education in Bulgaria depends on the economic stabilization and growth, on the enthusiasm of both teachers and students sharing the will to be competitive on the European and even world market under the conditions of globalization as well as on their active involvement in the international collaboration networks.

\section{REFERENCES}

1. Becich, M. J. The role of the pathologist as tissue refiner and data miner: the impact of functional genomics on the modern pathology laboratory and the critical roles of pathology informatics and bioinformatics.- Mol Diagn, 2000, 5, No 4, 287-299.

2. Brittain, J. M., Norris, A. C. Delivery of health informatics education and training.- Health Libr Rev, 2000, 17, No 3, 117-128.

3. Callas, P. W., Ricci, M. A., Caputo, M. P. Improved rural provider access to continuing medical education through interactive videoconferencing.Telemed. J. E. Health, 2000, 6, No 4, 393-399.

4. Cheshmedzhiev, M. V. Opportunities and issues of telemedicine development in Bulgaria. MA thesis. Varna, Medical University of Varna, 2001. 93 p. (in Bulgarian).

5. Cooper, J. B., Barron, D., Blum, R., Davison, J. K., Feinstein, D., Halasz, J., Raemer, D., Russell, R. Video teleconferencing with realistic simulation for medical education.- $J$. Clin. Anesth., 2000, 12, No 3, 256-261.

6. Curran, V. R., Hoekman, T., Gulliver, W., Landells, I., Hatcher, L. Web-based continuing medical education. (II): Evaluation study of computer-mediated continuing medical education.-J. Contin. Educ. Health Prof., 2000, 20, No 2, 106-119.

7. Diete1, M., Nguyen-Dobinsky, T. N., Hufnagl, P. The UICC Telepathology Consultation Center. The International Union Against Cancer. A global approach to improving consultation for pathologists in cancer diagnosis.- Cancer, 2000, 89, No 1, 187-191.

8. Gomez, E. G., Clark, P. M. The Internet in oncology nursing.- Semin Oncol Nurs, 2001,17, No 1, 7-17.

9. Gorman, P. J., Meier, A. H., Rawn, C, Krumme1, T. M. The future of medical education is no longer blood and guts, it is bits and bytes. $-A m$. /. Surg., 2000, 180, No 5, 353-356.

10. Harris, J. M., Salasche, S. J., Harris, R. B. Can Internet-based continuing medical education improve physicians' skin cancer knowledge and skills?J. Gen. Intern. Med., 2001, 16, No 1, 50-56. 
11. Jenkins, J. M., Cook, J., Edwards, J., Draycott, T., Cahill, D. J. Medical education with the Internet: a pilot training programme in reproductive medicine.- Br. J. Obstetr. Gynaecol., 2001, 108, No 1,114-116.

12. Konig, S., Markus, P. M., Becker, H. Lehren und Lernen in der Chirurgie - das Gottinger Curriculum.- Chirurg, 2001, 72, No 5, 613-620.

13. Kronz, J. D., Silberman, M. A., Allsbrook, W. C, Epstein, J. I. A web-based tutorial improves practicing pathologists' Gleason grading of images of prostate carcinoma specimens obtained by needle biopsy: validation of a new medical education paradigm.- Cancer, 2000, 89, No 8, 1818-1823.

14. McPhee, W., Niihr, C. Globalization and the cultural impact on distance education.- Int J Med Inform, 2000, 58-59, 291-295.

15. Mileva, P., Tomov, D., Radkova, Zh, Stoyanova, G., Todorova, Zh,

Kuyumdzhieva, R. The virtual library of the Medical University of Varna - ideogenesis, presence, and future.- Scripta Sci Med (Varna), 2002, 34 (in press).

16. Miller, P. L. Opportunities at the intersection of bioinformatics and health informatics: A case study.- $J$ Am Med Inform Assoc, 2000, 7, 431-438 (cited after 1).

17. Moehr, J. R., Grant, A. Medical informatics and medical education in Canada in the $21^{\text {st }}$ century.- Clin Invest Med, 2000, 23, No 4, 275-280.
18. Pardue, S. L. The virtual revolution: implications for academe.- Poult Sci, 2001, 80, No 5, 553-561.

19. Patel, A. M. Using the Internet in the management of asthma.- Curr Opin Pulm Med, 2001, 7, No 1, $39-42$.

20. Rosser, J. C, Murayama, M., Gabriel, N. H. Minimally invasive surgical training solutions for the twenty-first century.- Surg Clin North Am, 2000, 80, No 5, 1607-1624.

21. Sekikawa, A., Aaron, D. J., Acosta, B., Sa, E., LaPorte, R.E. Does the perception of downloading speed influence the evaluation of web-based lectures?- Public Health, 2001, 115, No 2, 152-156.

22. Tomov, D. T. Internationalization of interdisciplinary scientific communications (the case of testicular morphology). PhD thesis. Sofia, Centre for Science Studies and History of Science, Bulgarian Academy of Sciences, 1998.

23. Unwin, L., K. Stephens, N. Bolton. The role of the library in distance learning. A study of postgraduate students, course providers and librarians in the UK. London, etc., Bowker-Saur, 1998. 256 p.

24. Ward, J. P., Gordon, J., Field, M. J., Lehmann, H. P. Communication and information technology in medical education.- Lancet, 2001, 357, No 9258, 792-796. 